\title{
What Should A BBA Graduate Be Able To Do?: \\ These Competencies Are Essential
}

Robert W. Caldwell, Jr., (E-Mail: caldwell@ universe.uiwtx.edu), University of the Incarnate Word Jan R. Moore, (E-Mail: jmoore@ sosu.edu), Southeastern Oklahoma State University Michael Schulte, (E-Mail: mschulte@ concentric.net), University of the Incarnate Word

\begin{abstract}
University Schools of Business Administration are continually responding to the demands of stakeholders concerning the quality of the education embodied in the Bachelor of Business Administration degree. This collaborative paper discusses the competencies that are considered essential from the viewpoint of four stakeholders: accrediting agencies, faculty/administration, employers, and students/graduates. The authors present and support their views on competencies-identifying, achieving, assessing, and maintaining currency-in preparing future business leaders.
\end{abstract}

\subsection{Background}

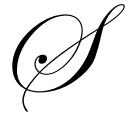

outheastern Oklahoma State University in Durant, Oklahoma (SOSU) and the University of the Incarnate Word (UIW) in San Antonio, Texas both offer business programs at the baccalaureate and graduate level and are accredited by the Association of Collegiate Business Schools and Programs (ACBSP). SOSU is accredited by the Commission on Institutions of Higher Education of the North Central Association of Colleges and Schools and UIW is accredited by the Southern Association of Colleges and Schools.

A more detailed description of both universities and their quality initiatives is contained in a previously published International Business and Economics Research Journal article focusing on assessing business degree outcomes (Caldwell, Moore, \& Schulte, 2003). Pertinent update information regarding these two schools' progress is as follows:

The School of Business at SOSU conferred 44 Bachelor of Business Administration degrees in the Spring of 2003 and 341 students were enrolled in business degree programs. The School of Business at UIW conferred 104 Bachelor of Business Administration degrees in the Spring of 2003 and 1,041 students were enrolled in business degree programs.

\subsection{Expected Competencies}

The Association to Advance Collegiate Schools of Business (AACSB)

Because the SOSU School of Business is preparing to enter pre-candidacy for accreditation by AACSB, we are including a discussion of those competencies first. The AACSB approach to accreditation is based on a current list of 21 standards as adopted on April 25, 2003. The Assurance of Learning Standards subsections of both Section 2: Standards for Business Accreditation and Section 3: Standards for Business Accreditation With Interpretive Information contains the pertinent standards of which the following are most appropriate for consideration in this paper (Eligibility Procedures and Standards for Business Accreditation, 2003). 


\section{Section 2: Standards for Business Accreditation}

Standard 15: Management of Curricula - does not specify which courses are to be taught, but it does require skills and general knowledge that normally result from the learning experiences provided by a school. These knowledge and skill areas include communication, reasoning, analytical, and reflective thinking abilities. Other areas include ethical understanding, legal responsibilities, information technology use and an understanding of multicultural and diversity issues.

The students should encounter learning experiences that integrate the areas of productivity, distribution, and services to create value. They should develop an understanding of financial theories to include markets, analysis and reporting. Decision-making supported by management science and statistical data analysis should be included as well as individual and group dynamics and the organizational environments of domestics as well as global businesses. Students should learn the importance and impact of information technologies to management. Other areas of knowledge may be identified and included as the school determines them to be necessary.

Standard 16 (Knowledge and Skills) concerns itself with the adaptation of learning goals to the school mission and to the school culture (Bachelor's or undergraduate level). Standard 17 addresses the requirement for the provision of adequate time, content, effort by students and interaction between them and the faculty to insure accomplishments of learning goals, again at the Bachelor's or undergraduate level.

\section{Section 3: Standards for Business Accreditation With Interpretive Information}

Learning expectations and the assurance they have been realized are elaborated upon for the various levels of business education. The bachelor's level is one that prepares the student for a career in business. The program expectations start with the pre-collegiate education of the student as a foundation upon which to build in order to prepare them to enter and pursue a career in the world of business. They are further expected to make positive contributions to society. They are to be able to organize, communicate and deal with the uncertainty that exists in the business world. The student is further expected to be capable of continued intellectual development at a higher level. Specifics regarding the above Standards of 16 and 18 address learning goal development and integration with the university mission. This section is very inclusive as it covers not only standards but also the intent of the school, defines program similarities and differences, and covers faculty responsibility for learning goals and their operationalization through the application of assessment measures that they adopt or develop. The determination of the goals is only the beginning as the care with which they are determined is of no importance without operationalizing them. This operationalization "is the ultimate step in the definition process...making them operational through actual measurement is the definition" (Eligibility Procedures and Standards for Business Accreditation, 2003, p. 58).

\section{Association of Collegiate Business Schools and Programs (ACBSP)}

Since both SOSU and UIW are accredited by ACBSP, the following discussion of what is required ACBSP applies to both schools. The ACBSP approach to acquiring and maintaining accreditation is dependent on the level to which their graduates achieve these requirements that ACBSP has deemed acceptable. "The standards and criteria draw heavily from the Malcolm Baldrige National Quality Award Education Criteria and the Missouri Quality Award" (p. 5). Due to the diversity and mission of universities already accredited or seeking additional accreditation and those universities initially seeking accreditation, ACBSP offers options, A or B. Option A is the more traditional approach and normally a university beginning with Option A adheres to that option throughout the process. The same would apply when selecting option B. Specific competencies are not addressed within the accreditation standards; however there are Common Professional Components (CPCs) within Section 6.1 Education Design and Delivery that require a minimum coverage of two thirds of a 3 semester hour course (or equivalent) in Option A. These twelve CPCs are grouped by four categories: Functional, Business Environment, Technical Skills, and Integrative Areas. Option B requires describing how the undergraduate business school or program address student needs for a curriculum of sufficient breadth and depth to provide for both learning skills and entry level 
business skills while meeting high standards. (ACSBP Standards And Criteria For Demonstrating Excellence In Baccalaureate / Graduate Degree Schools And Programs, 1998).

\section{Essential BBA Competencies}

The need to address competencies while continuing to add quality and value to the business programs is prevalent at both universities, especially when striving to produce the most qualified business graduates and being able to assess those outcomes. Keeping these competencies current and even more desirable, ahead of what is going on in the business world, is extremely important. Effectively meeting and translating accreditation standards into specific competencies requires the active participation of stakeholders and students and presents opportunities to fulfill three of the eleven core values and concepts in ACBSP accreditation, namely; Continuous Improvement and Organizational Learning, Faculty and Staff Participation and Development, and Partnership Development (ACSBP Standards And Criteria For Demonstrating Excellence In Baccalaureate / Graduate Degree Schools And Programs, 1998; Argyris, 1999; Argyris, \& Schon, 1996; Senge, 1990; Senge, McCabe, Lucas, Smith, Dutton, \& Kleiner, 2000).

A concept diagram (Figure 1: BBA Competencies), based on the strategic business analysis process used in UIW's Capstone Course, outlines this iterative, dynamic, and reflective process.

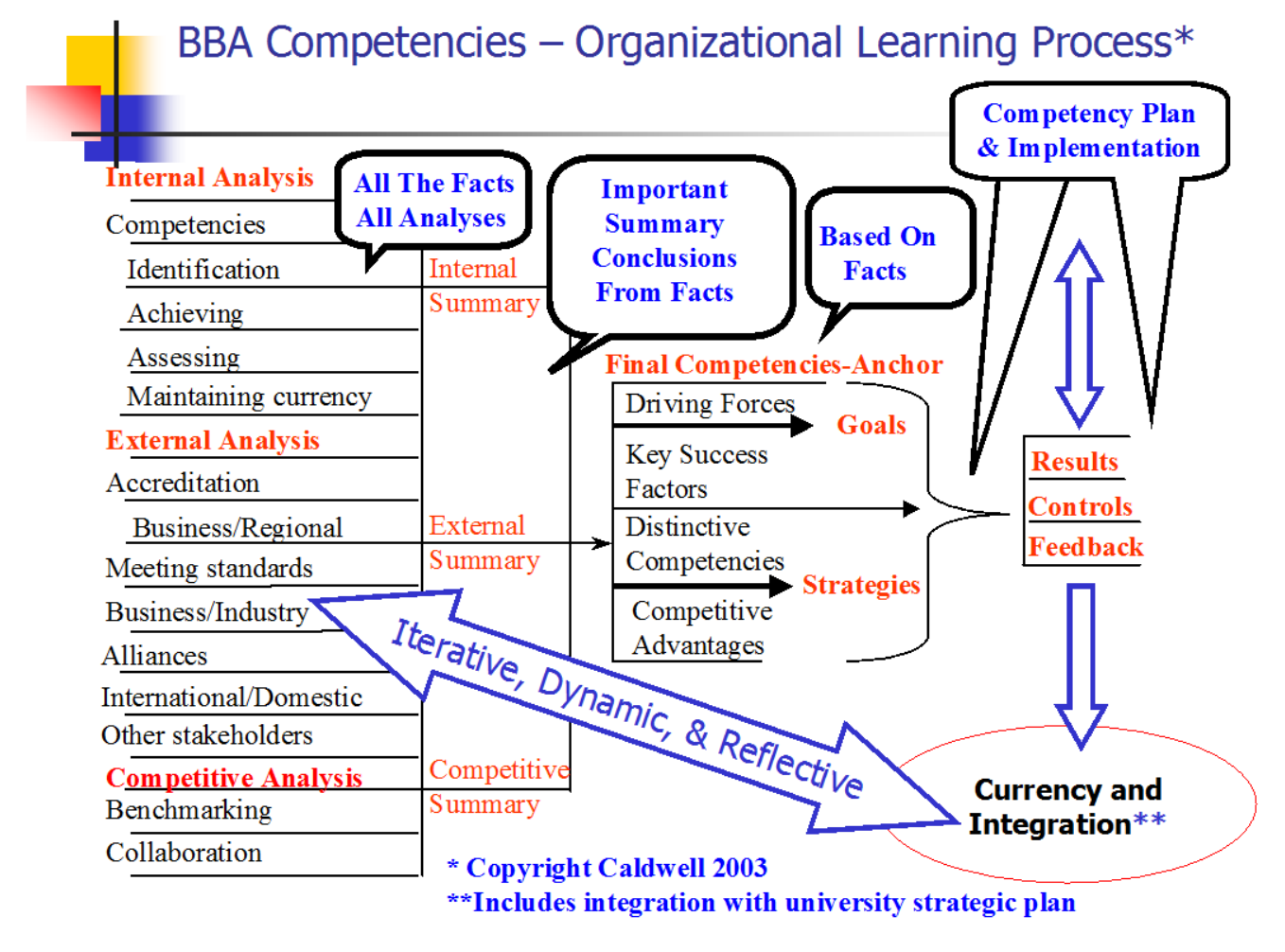

Figure 1: BBA Competencies

At UIW, the recently revised competency goal states "Students in the business program at UIW will be able to demonstrate the fundamental practices of business after completion." Also at UIW, the university has elected to pursue ACBSP Accreditation Option B. In conjunction with this, the university is pursuing a new strategic initiative under the Business Advisory Council to more actively involve local business and alumni, an effort that should improve and refine objectives and lead to new and improved benefits to all stakeholders. This initiative includes a biennial business/alumni survey designed in its methodology to better identify and measure competencies, evaluate 
critical elements, insure the mission / vision of the university is upheld and enhanced, and transform / change from a prescriptive to a more descriptive approach. Though the idea of the business survey is not new, the qualitative and quantitative process in which it is being done is, benefiting the end user and all stakeholders, using the Baldrige based criteria, and improving outcomes assessment. Following a successful sampling method (pilot), the initial results are expected for in-depth analysis in September of 2003 (H-E-B School of Business, 2003).

Each school's success in producing graduates that meet ACBSP accreditation standards is fundamental to maintaining accreditation. However, the competencies expected by stakeholders including prospective employers advisory groups and faculty members experienced in the requirements for graduates entering the business workforce, establish a critical set of outcomes for BBA graduates. The following discussion focuses on these competencies, which, although not derived from directly accreditation guidelines, are considered essential to student career success.

The authors believe that a student graduating with a BBA degree in Management should be capable of showing knowledge and comprehension of the various laws, theories, principles, and concepts important to the field of management. They should be able to extrapolate from those abstracts in order to apply them in business/management environments.

A graduate should be skilled in recognizing organizing principles applicable to information data and to be able to synthesize such information into reports for planning and operations. They should be able to implement those plans and to evaluate plans and their operations using internally derived evidence in order to apply it to opportunities and problems that exist external to the organization.

Intellectual honesty, objectivity and open-mindedness are required to make value judgments leading to ethical decisions in managing an organization in a manner that best serves that organization and society. Graduates must be skillful in acquiring, organizing and analyzing information and must have the interpersonal skills to work effectively in a team environment as both a team member and as a leader. They must realize the limitations of theory and must be skilled in technology in order to analyze and solve problems. This is especially important with regard to anticipating and identifying problems or potential problems and taking appropriate steps to resolve them.

To sum up, the graduate with a BBA degree must know, understand, and be able to apply the following essential BBA competencies:

- management and supervisory techniques

- leadership and decision making skills

- research and analytical skills to assess effectiveness and provide rationale to support decision-making

- oral and written communication skills in order to make presentations of topics of varying complexity

- current technology application skills

- skills to enable them to function effectively in the organization, business and industry environments

\subsection{Assessing Competencies}

Both SOSU and UIW employ the Capstone Course concept assessing students' competencies prior to graduation. At SOSU, the Capstone Course is a valuable assessment tool as it integrates the skills and knowledge gained from all the courses representing many disciplines that are required in fulfillment of their degree plans (Undergraduate Bulletin 2000-2002, Volume 83, July 2000). The traditional approach has been to use case studies in the capstone course. A trial class was conducted in the Summer 2003 semester testing a computer simulation instead of case studies. This program provides a multi-functional simulation of an electronics component manufacturing firm that can cover up to an eight-year business period. The simulation is very flexible in terms of level of difficulty, and number of functional units and other considerations i.e. the addition of a requirement for union negotiations, if desired. This trial period is expected to include Fall 2003 capstone classes. 
At UIW, the Capstone experience is also considered as an essential assessment vehicle (Undergraduate Bulletin 2001-2003, Volume 7, Number 1, July 2001). So much so, that the concept has been expanded to include two distinctive three-hour course to be taken in the final year before graduation. Course content during the first course centers on developing students' competence in applying their knowledge of the discipline-specific education (principles and practices). This is demonstrated by preparing in-depth analysis of an assigned business and industry with the objective of providing comprehensive rationale for goals and strategies that are then presented to senior decision makers. Once this competence is established, additional rigorous examination of various functional areas of business is performed.

The second course requires students to examine the differences among various industries by continuing to apply the fundamental integrative analytical process developed previously. A final comprehensive project completes the assessment of each students' competencies in decision-making and communicating the business analysis.

Testing, in various forms, is also used to determine the level of competence students possess. At SOSU, the Educational Testing Service (ETS) Exit Examination is administered during the students' graduating year, preferably in the last semester. Quality of instruction has long been a concern and the Exit Examination results have been regarded as one indication of instructional quality. It is important to note that the ETS Exit Examination is conducted in conjunction with Capstone course and the results are included in the grading scheme for the Capstone course.

Additionally, the Senior Exit Survey has been used in conjunction the ETS Major Field Test to assist in the effort to graduate students who are highly qualified. This instrument was revised in Fall 2001 to improve the assessment of student satisfaction with the academic programs and with university services. The survey also is intended to reveal any obstacles that would inhibit student success and to determine student post graduation goals. Pilot testing of the updated survey instrument was conducted in the Spring 2002 semester. This revised survey was accepted for implementation in Fall 2002 for Management, Marketing, and Business Information Management graduating seniors (Program Outcome Assessment Report for Fall 2001/Spring 2002, October 2002).

Assessment information regarding upper level business students is also collected through our internships that require the students to report their activities in detail. They also require the employer to evaluate the student in areas considered important for accurate assessment.

Presently, UIW is in the process of establishing a testing scheme similar to that currently used at SOSU. This testing is expected to begin in 2004 with administration planned for the second Capstone course. Internships are also used to gather competency assessment from employers of student interns, however, internships often occur in the junior years and therefore, can be influenced by a students' lack of certain applicable course work.

Both universities actively use advisory boards and student organizations to review, assess, and up-date BBA programs and guidance. UIW has recently enhanced its business programs by establishing a relationship with the H-E-B Corporation, a leading grocery retail firm, resulting in the creation of the H-E-B School of Business. This partnership is expected to yield positive growth and improvement in the quality of BBA graduates.

\subsection{Conclusions}

Clearly, compliance with standards is essential to maintaining accreditation in ACBSP or, in this case of SOSU, gaining accreditation by AACSB. It is also apparent, that experienced practitioners play a major role in shaping the competencies of the graduates of the respective BBA programs. Further, the focus of the both schools is on developing the students' competencies in comprehensive integrative analysis directed toward supporting executive decision making. The use of Capstone courses forms the core arena for demonstrating these competencies. The Capstone course concept is augmented by the use of nationally normed testing and inputs from various advisory groups including strategic alliances with corporate enterprises. 
Exit testing as well as the use of a combination of entrance and exit testing to determine value-added by the educational process offer potential for future assessment. This expansion of the employment of tests is the subject for a future study by the authors.

\subsection{References}

1. ACSBP Standards And Criteria For Demonstrating Excellence In Baccalaureate / Graduate Degree Schools And Programs. (1998). Available from http://www.acbsp.org/stds_4year.html\#b

2. Argyris, C. (1999). On organizational learning. (2nd ed.). Oxford, UK: Blackwell Publishers, Limited.

3. Argyris, C., \& Schon, D. A. (1996). Organizational learning II: Theory, method, and practice. Reading, MA: Addison-Wesley Publishing Company.

4. $\quad$ Caldwell, R. W., Moore, J. R., \& Schulte, M. (2003). Assessing undergraduate business degree outcomes: A comparison of two universities. International Business And Economics Research Journal 2 (5), (67-74).

5. Eligibility Procedures and Standards for Business Accreditation. (2003). The Association to Advance Collegiate Schools of Business International. Available from http://www.aacsb.edu/accreditation/brc/standards-4-25.pdf

6. H-E-B School of Business. (2003). Strategic Plan. San Antonio, Texas: University of the Incarnate Word

7. Program Outcome Assessment Report for Fall 2001/Spring 2002. (October 2002). Southeastern Oklahoma State University.

8. Senge, P. M. (1990). The fifth discipline: The art and practice of the learning organization. New York: Doubleday.

9. Senge, P. M., McCabe, N., Lucas, T., Smith, B., Dutton, J., \& Kleiner, A. (2000). Schools that learn: A fifth discipline fieldbook for educators, parents, and everyone who cares about education. New York: Doubleday.

10. Undergraduate Bulletin 2000-2002, Volume 83. (July 2000). Durant, OK: Southeastern Oklahoma State University. Available at www.sosu.edu/

11. Undergraduate Bulletin 2001-2003, Volume 7, Number 1. (July 2001). San Antonio, TX: University of the Incarnate Word. Available at www.uiw.edu/ 